Check for updates

Cite this: J. Mater. Chem. A, 2017, 5 , 10622

Received 21st March 2017

Accepted 24th April 2017

DOI: $10.1039 / \mathrm{c} 7 \mathrm{ta0} 2488 \mathrm{f}$

rsc.li/materials-a

\section{Large-scale fabrication of translucent and repairable superhydrophobic spray coatings with remarkable mechanical, chemical durability and UV resistance $\dagger$}

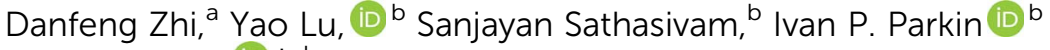 \\ and Xia Zhang (D) *ab
}

In this work, we present a simple and effective silica-polymer-based spray coating to create a translucent, mechanically durable, chemically stable, healable and environmentally friendly superhydrophobic coating with UV resistance. The coatings retained superhydrophobicity after UV radiation for at least 175 hours, heating up to $150{ }^{\circ} \mathrm{C}$, exposure to strong acids and bases, and various mechanical durability tests such as knife scraping, hand kneading, and multiple cycles of tape peeling 100 times. In addition, the coating treated sponge was used for continuous oil-water separation through connection with a vacuum system, the separation efficiency was greater than $95 \%$ for various liquid hydrocarbons. This substrateindependent spray coating is believed to be useful for large-scale application for both outdoor and indoor applications.

\section{Introduction}

Coating is an essential step in adjusting the surface properties of materials. ${ }^{1}$ Lotus leaf-inspired superhydrophobic coatings have attracted much attention in recent years due to their various applications, such as self-cleaning, ${ }^{2,3}$ anti-fogging, ${ }^{4}$ delayed frosting, ${ }^{5}$ anti-corrosion, ${ }^{6,7}$ etc. However, poor durability, high fabrication costs, and difficulties in maintaining the air cushions have restricted large-scale applications of superhydrophobic surfaces. ${ }^{8-10}$ To expand the lifespan of superhydrophobicity, one approach is to get the monoliths of a material that possesses low surface-energy microstructures that extend throughout its entire volume. If the uppermost layer is damaged or removed upon scraping by abrasion, the newly exposed rough surface with low surface-energy is also waterrepellent, thereby making the superhydrophobicity more stable. ${ }^{11,12}$ Another approach to improve the durability of superhydrophobicity is to endow the surface with a self-healing ability. When the surface loses superhydrophobicity, it can be healed by external stimulus, including $\mathrm{pH}$, enzymes, heating, light irradiation, and redox activities. ${ }^{13,14}$ For example, Li et al. ${ }^{15,16}$ fabricated superhydrophobic coatings with preserved

${ }^{a}$ National \& Local Joint Engineering Research Center for Applied Technology of Hybrid Nanomaterials, Henan University, Kaifeng 475004, P. R. China. E-mail: xia.zhang@ ucl.ac.uk

${ }^{b}$ Department of Chemistry, University College London, 20 Gordon Street, London, WC1H OAJ, UK

$\dagger$ Electronic supplementary information (ESI) available. See DOI: $10.1039 / \mathrm{c} 7 \mathrm{ta0} 2488 \mathrm{f}$ self-healing agents of reacted fluoroalkylsilane (FAS) in the coatings, which were porous and ridged. Once the primary top FAS layer was decomposed, rendering the surface hydrophilic, the preserved healing agents could migrate to the coating surface in a humid environment to heal the superhydrophobicity of the coating.

Superhydrophobic organic-inorganic hybrid composite coatings have received much more attention because of the simultaneous advantages of both inorganic and organic materials. ${ }^{17,18}$ Using inorganic nanoparticles to create nano- or microscale structures on organic polymer coatings is a concept for fabrication of hybrid superhydrophobic nanocoatings. ${ }^{1920}$ However, the inorganic nanoparticles have difficulty to cooperate with the organic polymer materials, which leads to phase separation during the curing process. To resolve this problem, surface functionalization is required to endow nanoparticles with hydrophobicity. ${ }^{16}$ Unfortunately, such hydrophobized nanoparticles rely on compounds that are either expensive or harmful to the environment (e.g., perfluorooctanoic acid).$^{11}$ In consideration of the practical conditions, superhydrophobic coatings are expected to be applied both for outdoor and indoor applications. In terms of outdoor applications, for example, superhydrophobic surfaces could be used on transmission lines for anti-icing purposes. ${ }^{21}$ This requires a superhydrophobic coating that can be applied on a large scale with good mechanical robustness, UV resistance and stability to corrosive liquids such as acids and bases. In consideration of indoor applications, superhydrophobic surfaces are expected to be 
used for water proofing and self-cleaning purposes and even with some translucency as shower room glass.

One of the most important potential applications of superhydrophobic surfaces is for oil-water separation, which usually involves the use of a superhydrophobic-oleophilic mesh or membrane. ${ }^{22,23}$ However, the mesh/membrane systems can hardly be used for continuous oil-water separation, and may require some water/oil collection or disposal processes, which results in some energy and economic costs. ${ }^{24-27}$

Here, we demonstrate a simple and effective spray process to create a translucent, mechanically durable, chemically stable, healable and environmentally friendly superhydrophobic coating with remarkable UV resistance. The spray was fabricated using functionalized $\mathrm{SiO}_{2}$ nanoparticles and fluorine-free polymers, and can be easily treated on both hard (glass and copper) and soft substrates (cotton, textile and sponge). The coatings retained superhydrophobicity after intense UV radiation for at least 50 hours, heating up to $150{ }^{\circ} \mathrm{C}$, exposure to strong acids and bases, and various mechanical durability tests such as knife scraping, hand kneading, and multiple cycles of tape peeling for at least 100 times. In addition, the coating treated sponge was used for continuous oil-water separation through connecting with a vacuum system, the separation efficiency was above $95 \%$ for various liquid hydrocarbons in water, including silicone oil, methylbenzene, trichloromethane, $n$ hexane, paraffin oil and dichloromethane.

\section{Experimental section}

\subsection{Preparation of superhydrophobic silica powder}

Sodium silicate was dissolved in $50 \mathrm{~mL}$ of deionized water to form a $0.15 \mathrm{~mol} \mathrm{~L}^{-1}$ solution (defined as Solution A). Then 25 $\mathrm{mL}$ of $0.18 \mathrm{~mol} \mathrm{~L}^{-1}$ hydrochloric acid (Solution B) was added dropwise into the stirred Solution A. After half of Solution B was added, $25 \mathrm{~mL}$ of $0.0125 \mathrm{~mol} \mathrm{~L}^{-1}$ hexamethyldisilazane (HMDS) was added to Solution A together with the rest of Solution B dropwise. The suspension was heated to $60^{\circ} \mathrm{C}$ and was stirred for $4 \mathrm{~h}$. After cooling down to room temperature, the suspension was separated into two layers with a white foam layer floating on top. The foam was collected by filtration and washed repeatedly using a mixed solution of deionized water and ethanol until $\mathrm{Cl}^{-}$could not be detected using silver nitrate solution by visual examination. The filtered cake was redispersed into a mixed solution of deionized water and ethanol at a volume ratio of $1: 1$ to form an emulsion. Finally, the emulsion was spray-dried and hydrophobic silica nanoparticles were obtained.

\subsection{Preparation of superhydrophobic $\mathrm{SiO}_{2} /$ polyurethane (PU) coatings}

The durable superhydrophobic $\mathrm{SiO}_{2} / \mathrm{PU}$ coating was fabricated by a simple spray method. In the synthesis of the suspension, $0.8 \mathrm{~g}$ of hydrophobic silica nanoparticles, $1.7 \mathrm{~g}$ of the polyurethane pre-polymer and $0.17 \mathrm{~g}$ of 4,4'-methylene bis(2chloro-benzenamine) as a curing agent were added into $15 \mathrm{~g}$ of acetone, and the mixture was magnetically stirred for $30 \mathrm{~min}$ at room temperature to make a uniform suspension. The suspension was sprayed onto the substrates with a $2.5 \mathrm{M} \mathrm{Pa}$ compressed air gas using a spray-gun with a nozzle diameter of about $0.8 \mathrm{~mm}$. The distance between the spray gun and the substrates was about $15 \mathrm{~cm}$. The coatings were finally cured at $150{ }^{\circ} \mathrm{C}$ for $1 \mathrm{~h}$. For soft materials such as paper, fabric, cotton and sponge, the substrates were initially ultrasonicated into the suspension for $3 \mathrm{~min}$, and then cured at $150{ }^{\circ} \mathrm{C}$ for $1 \mathrm{~h}$.

\subsection{Preparation of silica/epoxy resin superhydrophobic coatings}

$1.8 \mathrm{~g}$ of epoxy resin, $0.54 \mathrm{~g}$ of the curing agent and $0.54 \mathrm{~g}$ of hydrophobic silica nanoparticles were dispersed in $15 \mathrm{~g}$ of acetone to make a uniform suspension. The suspension was sprayed onto the hard and soft substrates and then followed by a curing process. The conditions of spray coating and the curing processes are the same as those used in the silica/PU coating preparation.

\subsection{Characterization}

The surface morphology of the samples was examined with a field emission scanning electron microscope (FESEM, JSM6701F). The surface components of the samples were analyzed with an X-ray photoelectron spectrometer (XPS, AXIS ULTRA). Thermogravimetric (TG) measurements were done with NETZSCH STA $449 \mathrm{C}$ using a dynamic heating rate of $10{ }^{\circ} \mathrm{C} \mathrm{min}^{-1}$. The contact angles (CA) and sliding angles (SA) of water and other liquids (coffee, milk, vinegar, red wine, and cola) were measured using a DSA-100 optical contactangle meter (Kruss Company, Ltd, Germany) at room temperature $\left(22^{\circ} \mathrm{C}\right)$. The average CA value was determined by measuring the same sample at five different positions. The volume of all liquids was $8-10 \mathrm{~mL}$ when the contact angles and sliding angles were measured. The image of the droplet was obtained with a digital camera (NIKON, P600). UV radiation (obtained from a $8 \mathrm{~W} \mathrm{Hg}$ lamp with a wavelength of 254 $\mathrm{nm}$ ) was used to test the UV resistance of the prepared coatings, and the water contact angles of the coatings were measured every 10 hours of UV radiation. The transparency of the coatings was tested using a UV-vis spectrometer (UV1800PCS, Mapada Instruments). The transmittance of each sample was recorded at $340-800 \mathrm{~nm}$ and collected at ambient temperature.

\subsection{Sandpaper abrasion test}

The sandpaper abrasion tests were carried out on the $\mathrm{SiO}_{2} / \mathrm{PU}$ coating as well as the purchased commercial NeverWet coating. In this test, the coating weighing $300 \mathrm{~g}$ was placed face-down on the sandpaper (standard glass paper, grit no. 600) and moved for $23 \mathrm{~cm}$; the sample was rotated by $90^{\circ}$ (face to the sandpaper) and then moved for $10 \mathrm{~cm}$. This process is defined as one abrasion cycle, which guarantees the surface is abraded longitudinally and transversely in each cycle even if it is moved in a single direction. 


\subsection{Oil/water separation}

The average absorption capacity was determined by measuring the same sample at least five times. After being rinsed thoroughly with alcohol and dried, the as-prepared sponges could be reused for oil/water separation for many cycles.

\section{Results and discussion}

\subsection{Superhydrophobic silica/polymer composite coating}

Silica nanoparticles were fabricated via a simple process. ${ }^{28}$ Firstly, sodium silicate was hydrolyzed to form silicic acid under the acidic conditions. Condensation polymerization occured through hydration among the hydroxyls of the silicic acids in three dimensions and the $\mathrm{Si}$ and $\mathrm{O}$ were bonded to each other to form nano-silica clusters. Large numbers of hydroxyls were left on the surface of the nano-clusters, while the HMDS was hydrolyzed to produce trimethylsilyl and ammonia. As the nano-clusters formed, the trimethylsilyl reacted rapidly with the hydroxyl of nano-silica to form a modified layer on the surface of the clusters. Here, the trimethylsilyls substituted a majority of the active groups of silica and result in steric hindrance, which prevented the silica nanoparticles from continuously growing or agglomerating. Thus, the hydrophilic silica nanoparticles were transformed into superhydrophobic ones and had excellent compatibility with the organic solution. As shown in 1a, the silica nanoparticles can be dispersed in organic media such as carbon tetrachloride, liquid paraffin, hexane, and acetone to form a colourless solution. Fig. 1a inset shows a photograph of the obtained silica powder. The silica nanoparticles were hydrophobic and could be absorbed on the liquid/air interface leading to the formation of liquid "marbles", as shown in Video $S 1$ in the ESI. $\dagger$ In the TEM image (Fig. 1b), the silica clusters composed of nanoparticles had diameters of several tens of nanometers. The XRD pattern of the sample shows that the obtained silica is X-ray amorphous as shown in
Fig. 1c. Fig. 1d shows the thermogravimetric analysis image of the silica nanoparticles, the weight loss was $3.4 \%$ at $200{ }^{\circ} \mathrm{C}$ due to the surface absorption. There is a strong decrease between $200{ }^{\circ} \mathrm{C}$ and $700{ }^{\circ} \mathrm{C}$, which refers to the decomposition of the surface modification with a weight loss of $7.8 \%$. Fig. 1e shows the optical images of glass coated with a $\mathrm{SiO}_{2} / \mathrm{PU}$ coating with a thickness of about $7 \mu \mathrm{m}$ (Fig. S1a in the ESI $\dagger$ ), and all the letters show good readability under the coated glass. The transmittance spectrum of the coated glass in the visible region $(300-800 \mathrm{~nm})$ is a rational characterization of transparency as shown in Fig. 1f. Fig. 1g shows the optical images of glass coated with a $18 \mu \mathrm{m} \mathrm{SiO}_{2}$ /epoxy resin coating (Fig. S1b in $\mathrm{ESI} \dagger$ ), and the letters under the coating also show readability. The transmittance of the coated glass was about $70 \%$ as shown in Fig. 1 h.

Table 1(a) and (b) show the water contact angle and sliding angle of different substrates treated with a $\mathrm{SiO}_{2} / \mathrm{PU}$ and $\mathrm{SiO}_{2} /$ epoxy resin coating, respectively. It can be seen that all the contact angles were larger than $150^{\circ}$ as well as the sliding angles that were lower than $10^{\circ}$ on both hard substrates (glass and copper) and soft substrates (textile, paper, sponge, and cotton), indicating the excellent superhydrophobic performance.

Table 1 Water contact and sliding angles of a $\mathrm{SiO}_{2} /$ polymer coating on different substrates

\begin{tabular}{llllll}
\hline & \multicolumn{2}{l}{ (a) $\mathrm{SiO}_{2} / \mathrm{PU}$} & & \multicolumn{2}{l}{ (b) $\mathrm{SiO}_{2} /$ epoxy resin } \\
\cline { 2 - 3 } Substrate & $\mathrm{CA}\left({ }^{\circ}\right)$ & $\mathrm{SA}\left(^{\circ}\right)$ & & $\mathrm{CA}\left(^{\circ}\right)$ & $\mathrm{SA}\left(^{\circ}\right)$ \\
\hline Glass & $158.0 \pm 1.5$ & $1.52 \pm 0.5$ & & $158.8 \pm 1.5$ & $1.55 \pm 0.5$ \\
Copper & $155.3 \pm 1.5$ & $1.66 \pm 0.5$ & & $156.8 \pm 1.5$ & $1.56 \pm 0.5$ \\
Cotton & $153.8 \pm 1.5$ & $8.13 \pm 0.5$ & & $151.9 \pm 1.5$ & $8.05 \pm 0.5$ \\
Textile & $158.5 \pm 1.5$ & $6.25 \pm 0.5$ & & $151.7 \pm 1.5$ & $6.29 \pm 0.5$ \\
Paper & $153.3 \pm 1.5$ & $2.35 \pm 0.5$ & & $159.2 \pm 1.5$ & $2.52 \pm 0.5$ \\
Sponge & $151.7 \pm 1.5$ & $4.97 \pm 0.5$ & & $150.3 \pm 1.5$ & $5.25 \pm 0.5$
\end{tabular}
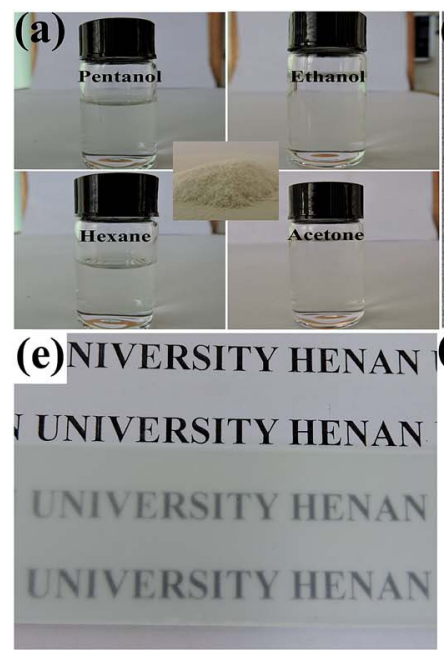
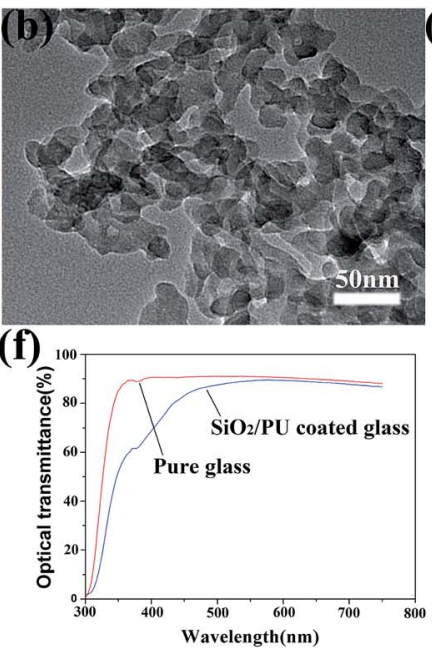
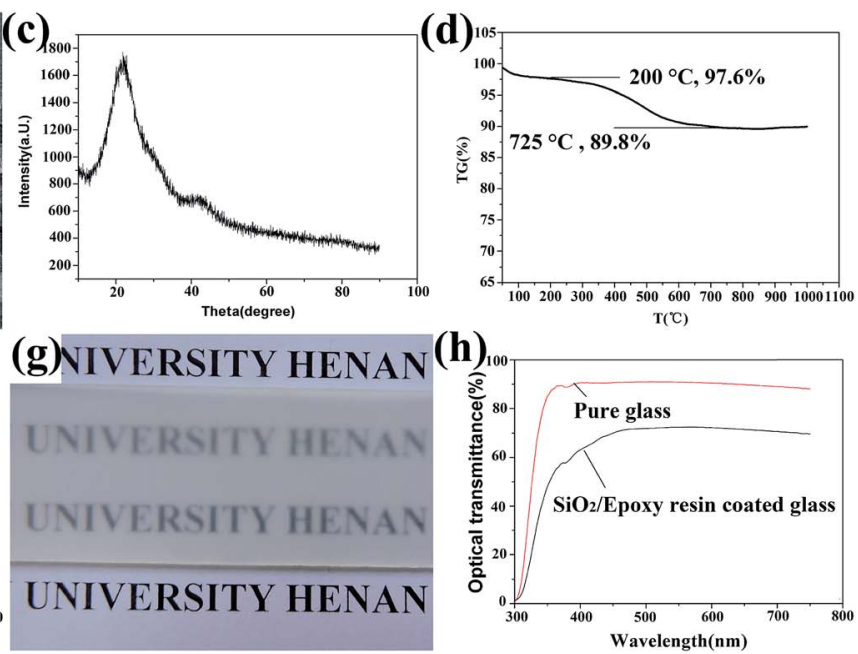

(h)

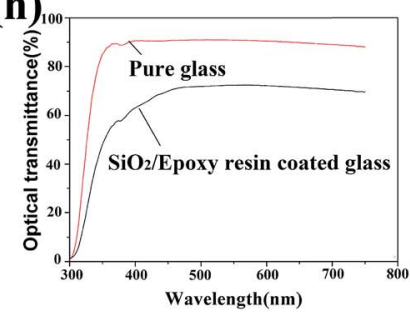

Fig. 1 (a) Digital photographs of the silica nanoparticles dispersed in pentanol, ethanol, hexane, and acetone, respectively. The inset is the photograph of the obtained silica powder. (b) TEM image, (c) XRD spectrum and (d) TG image of the silica nanoparticles. (e) Photograph of the $\mathrm{SiO}_{2} /$ polyurethane $\left(\mathrm{SiO}_{2} / \mathrm{PU}\right)$ coating on glass, $(\mathrm{f})$ transmittance spectrum of the glass slide before and after coating with $\mathrm{SiO} / 2 / \mathrm{PU}(\mathrm{g})$ photograph of the $\mathrm{SiO}_{2}$ /epoxy resin coating on glass. (h) Transmittance spectrum of the glass slide before and after coating with $\mathrm{SiO}_{2} /$ epoxy. 
Furthermore, the obtained coatings were shown to be highly repellent to a wide variety of liquids including coffee, milk, cola, red wine and vinegar (ESI Fig. S2 $\dagger$ ).

To understand the relationship between the mass fraction of $\mathrm{SiO}_{2}$ nanoparticles and the surface wettability, we measured the water contact angles with different mass fractions of $\mathrm{SiO}_{2}$ powder in PU and epoxy resin, respectively, as shown in Fig. S3. $\dagger$ When PU was used as the hydrophobic agent, the water contact angle increased as the mass fraction of $\mathrm{SiO}_{2}$ powder increased. The water contact angle reached $150^{\circ}$ when the mass fraction of $\mathrm{SiO}_{2}$ was increased to $30 \mathrm{wt} \%$, and it did not significantly change as the mass fraction of $\mathrm{SiO}_{2}$ nanoparticles further increased. When epoxy resin was used as the hydrophobic agent, the water contact angle did not reach $150^{\circ}$ until the mass fraction of $\mathrm{SiO}_{2}$ nanoparticles was increased to $20 \mathrm{wt} \%$, and it only increased slightly as the mass fraction of $\mathrm{SiO}_{2}$ nanoparticles further increased.
Fig. 2 shows the SEM image of different substrates (hard and soft) before and after being treated with a $\mathrm{SiO}_{2} /$ polymer coating. The original substrate surfaces were smooth, but they show highly textured surface morphologies after the treatments with hydrophobic silica nanoparticles. Hydrophobic silica nanoparticle aggregations contributed to both the surface roughness and the reduction of the surface free energy, which are the main factors responsible for superhydrophobicity. ${ }^{29}$ The inset is the photograph of the water droplet image and corresponding contact angle image, and it was found that after treatment with the coating, the soft and hard substrates became superhydrophobic with water contact angles larger than $150^{\circ}$. The thermal stability of the $\mathrm{SiO}_{2} / \mathrm{PU}$ and $\mathrm{SiO}_{2} /$ epoxy resin coating was tested by thermogravimetric analysis as shown in Fig. 3a and $\mathrm{b}$, respectively. As shown in Fig. 3a, there was no obvious weight loss before $200{ }^{\circ} \mathrm{C}$; between $240{ }^{\circ} \mathrm{C}$ and $450{ }^{\circ} \mathrm{C}$, it had a dramatic decrease, indicating the heat-induced decomposition

\section{(b) (a) (c)}

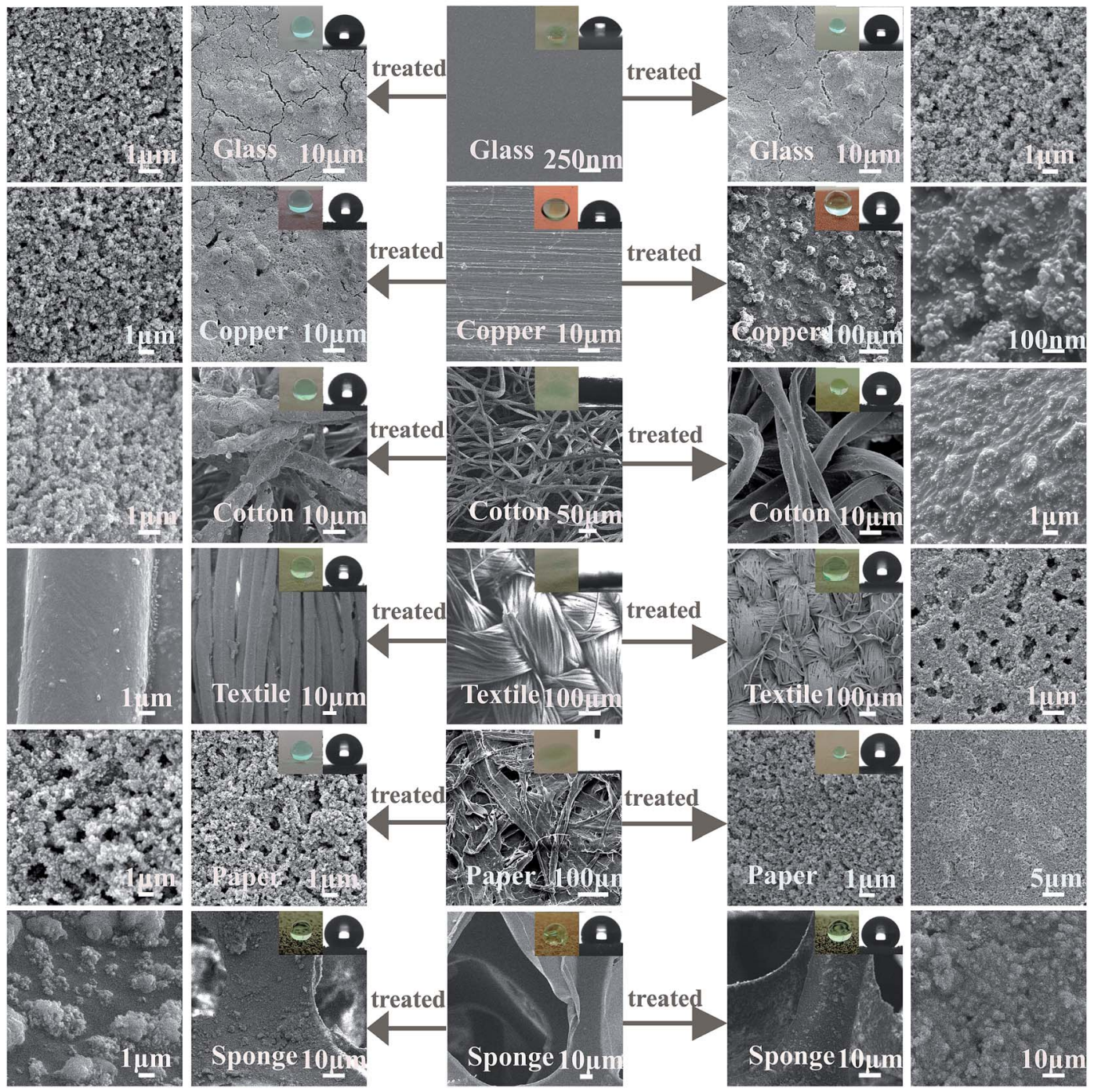

Fig. 2 Surface morphology of (a) original coating, (b) $\mathrm{SiO}_{2} / \mathrm{PU}$ and (c) $\mathrm{SiO}_{2}$ /epoxy resin coating treated samples on various substrates. 

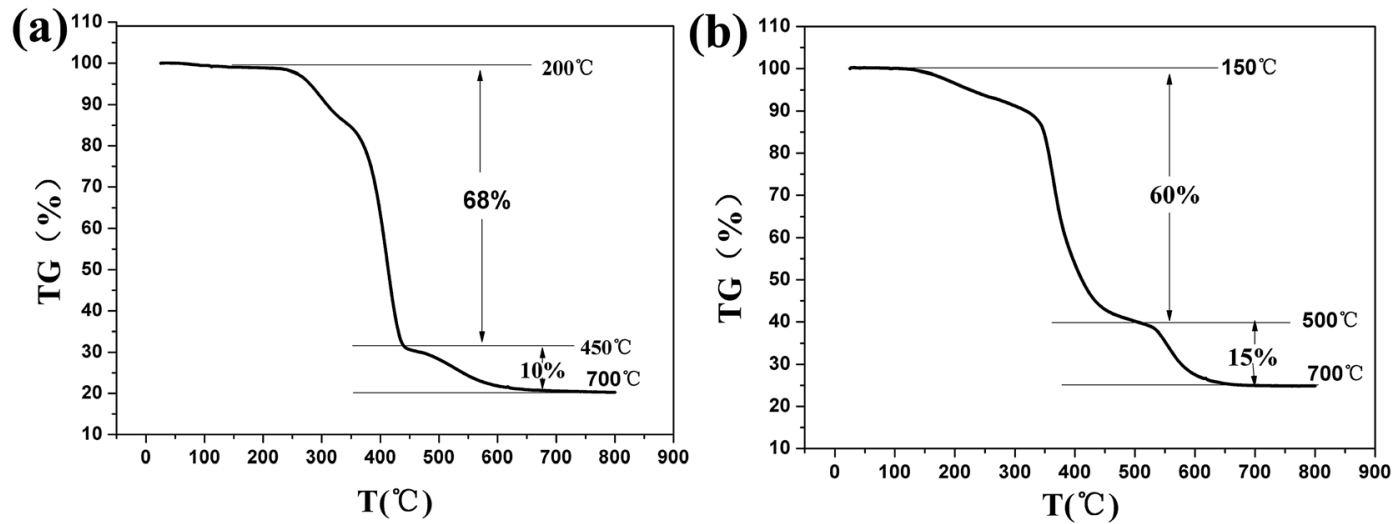

Fig. $3 \mathrm{TG}$ images of (a) $\mathrm{SiO}_{2} / \mathrm{PU}$ and (b) $\mathrm{SiO}_{2}$ /epoxy resin treated coatings.

of polyurethane with a $68 \%$ weight loss. Another strong decrease from $450{ }^{\circ} \mathrm{C}$ to $700{ }^{\circ} \mathrm{C}$ corresponded to further decomposition of polyurethane. Fig. $3 \mathrm{~b}$ shows the TG image of the $\mathrm{SiO}_{2}$ /epoxy resin. From $150{ }^{\circ} \mathrm{C}$ to $700{ }^{\circ} \mathrm{C}$, the total loss was about $75 \%$ corresponding to the burning of the epoxy resin, and the rest was the inorganic $\mathrm{SiO}_{2}$ component. Although the

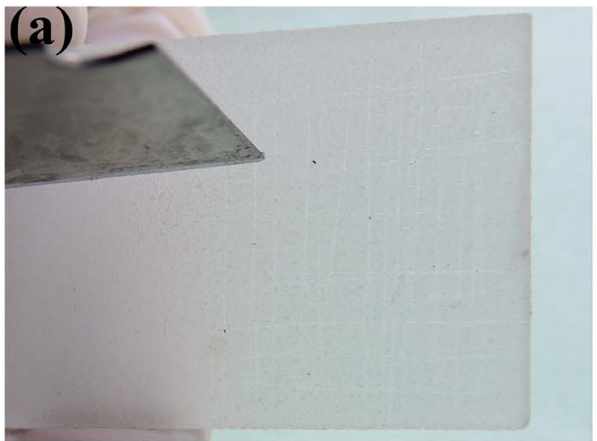

(c)
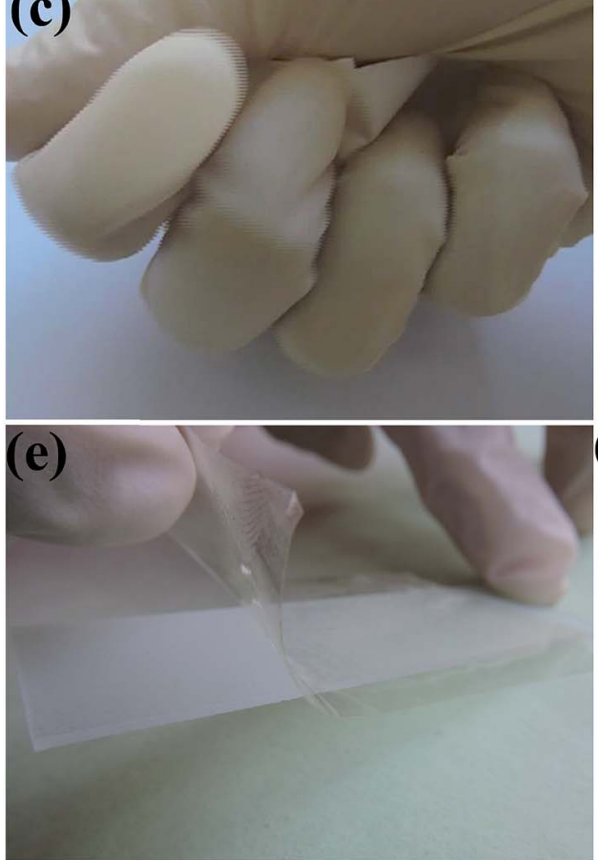
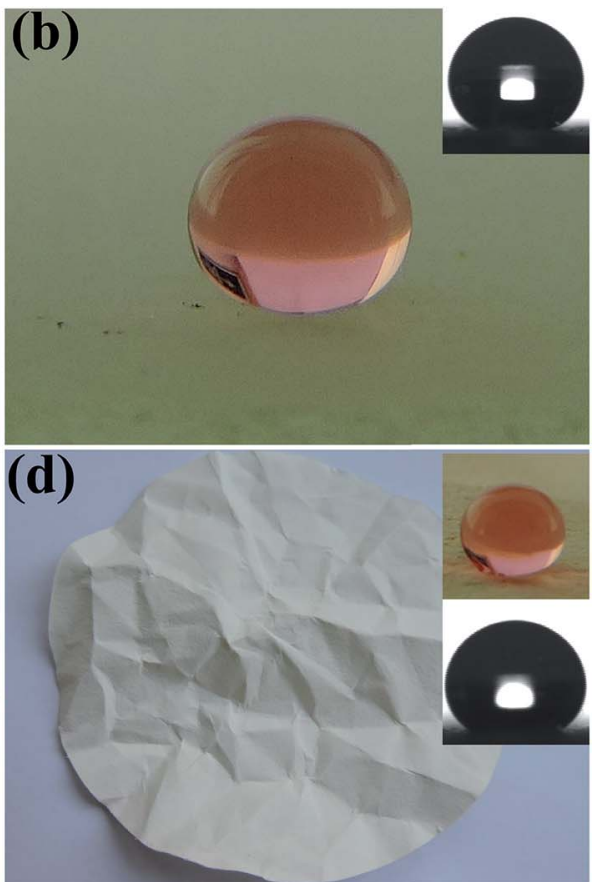

(f)

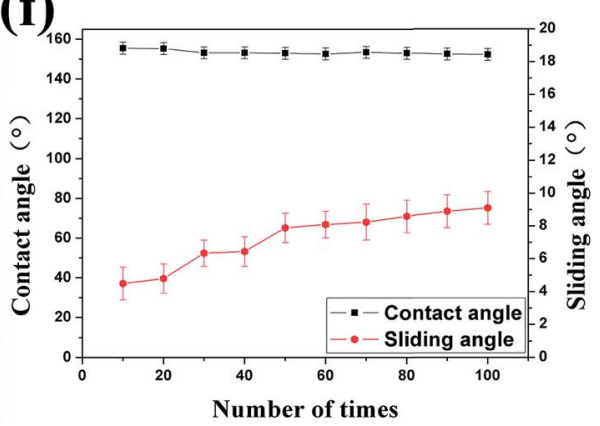

Fig. 4 Durability of the $\mathrm{SiO}_{2} / \mathrm{PU}$ coating. (a) Scratched by a knife. (b) Photograph of a water droplet sitting on the coating surface after knife scratching (inset is the corresponding contact angle optical image). (c) Kneading tests of a coated filter paper. (d) Photograph of the filter paper after kneading tests (inset is the water droplet and contact angle optical image). (e) Tape peeling test. (f) Water contact angles and sliding angles after multiple cycles of tape peeling tests. 
coating decomposed at high temperature, both $\mathrm{SiO}_{2} / \mathrm{PU}$ and $\mathrm{SiO}_{2} /$ epoxy resin coatings show significant heat resistance below $150{ }^{\circ} \mathrm{C}$, further providing evidence that the superhydrophobic coatings are sufficient for daily use.

\subsection{Mechanical durability and pH-tolerance}

Durability is an important factor that affects the practical application of superhydrophobic materials, especially mechanical friction that leads to the damage of the surface micro/nano structure, resulting in the loss of the superhydrophobicity. In this work, we used different methods to evaluate the durability of the superhydrophobic coatings such as abrasion, compression, adhesive tape peel, and corrosive attack. As shown in Fig. 4a-d and Videos S2 and S3 in the ESI, $\uparrow$ the coating on soft and hard substrates had good mechanical durability after induced damage such as knife scraping, folding, and kneading, and the coating still maintained its waterrepellency. In large-scale practical applications, the adhesion between coatings and substrates is one of the most important issues that should be considered. Here, we used multiple cycles of tape peeling to investigate the adhesion between superhydrophobic coatings and the substrates as shown in Fig. 4e. Fig. $4 \mathrm{f}$ shows the water contact angles and sliding angles of the superhydrophobic $\mathrm{SiO}_{2} / \mathrm{PU}$ sample after multiple cycles of tape peeling tests. The contact angles do not significantly change and remain above $150^{\circ}$ after 100 peeling cycles. The sliding angles increase with the peeling cycles, but remain below $10^{\circ}$, which suggests that the superhydrophobicity maintains a stable Cassie-Baxter state and that the coatings have strong adhesion to the substrate. Also, the coating has good mechanical durability, it was able to withstand at least 200 cycles of compression and release and maintained its superhydrophobicity unchanged (ESI Fig. S4†).

The sandpaper abrasion test was used to further examine the surface mechanical durability of our superhydrophobic coatings and compare it to those of the commercially available NeverWet superhydrophobic coating as shown in Fig. S5. $\dagger$ It was observed that the water contact angles of the $\mathrm{SiO}_{2} / \mathrm{PU}$ coatings remained above $150^{\circ}$ after 35 abrasion cycles, indicating that the super-hydrophobicity was retained after mechanical abrasion. Under the same abrasion conditions, the water contact angle of the commercial coating reduced to less than $150^{\circ}$ after only 20 abrasion cycles, indicating that its superhydrophobicity was lost. Therefore, our superhydrophobic coatings showed excellent abrasion resistance which is even better than that of the commercial products.

Long-term chemical durability is essential for superhydrophobic coatings to be used in practical applications especially in an outdoor environment. In this paper, we used corrosive liquids (acids and bases) to test the chemical durability of superhydrophobic coatings. Fig. 5 shows the water CA and sliding angle of the superhydrophobic coating as a function of continuous contact time with extremely corrosive liquids. It (a)
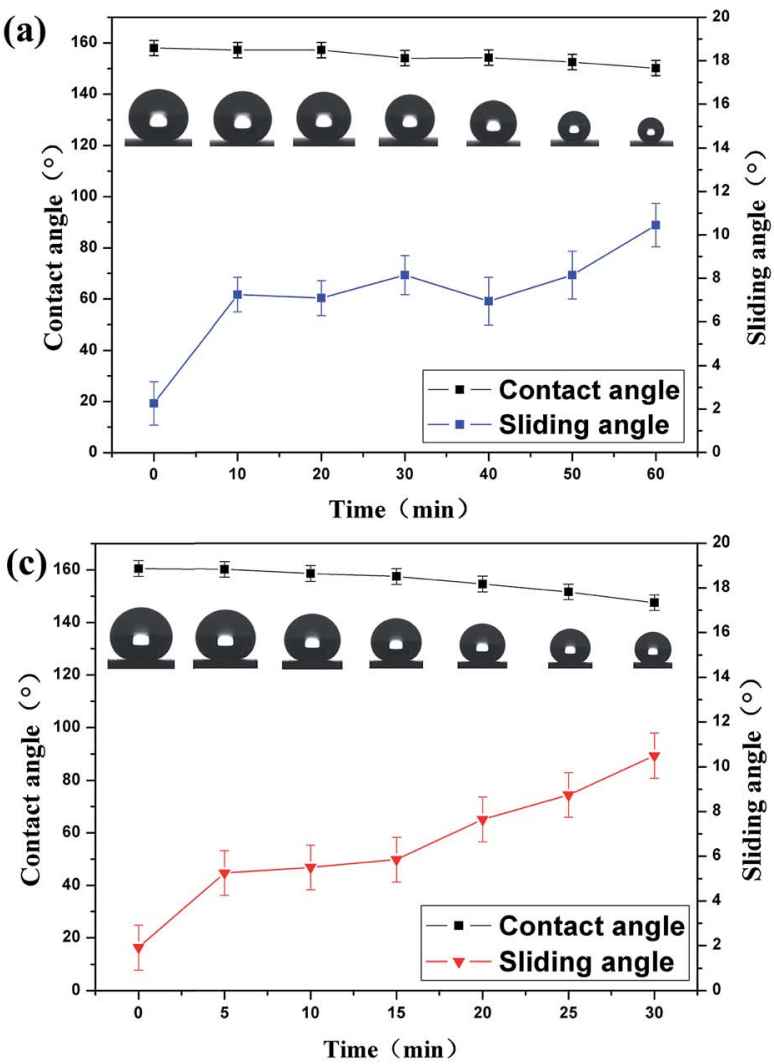

(b)
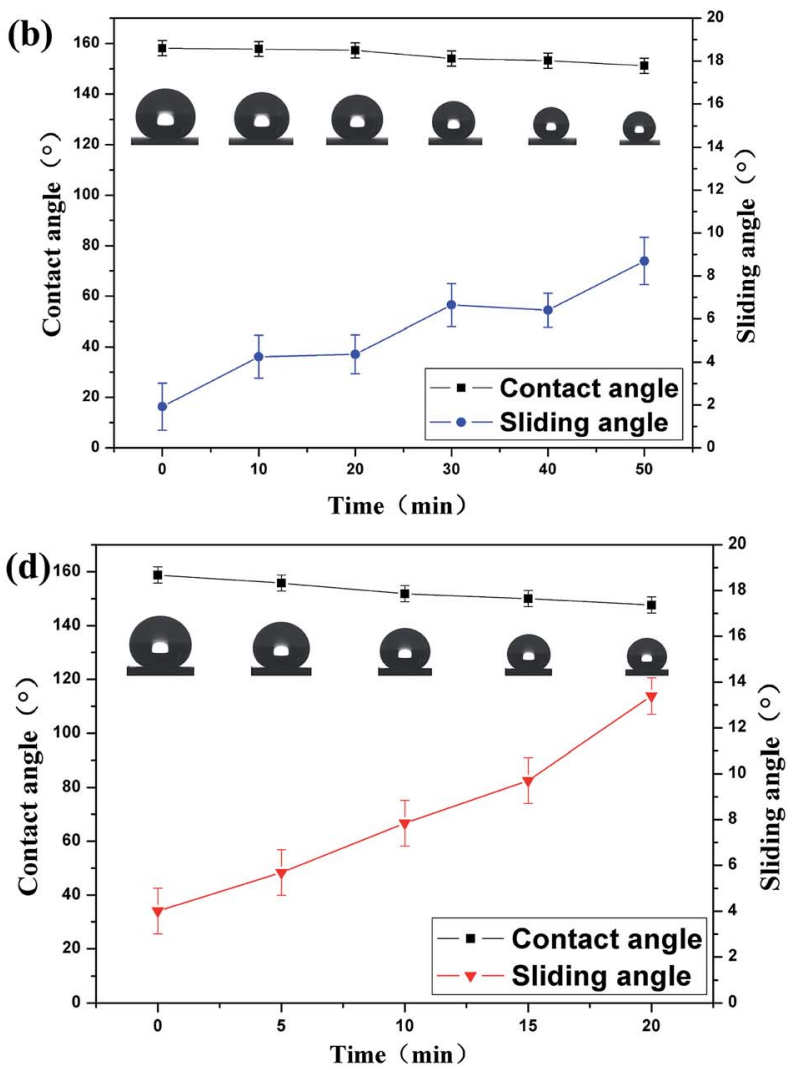

Fig. 5 Contact angles and sliding angles as a function of contact time with (a) acidic and (b) alkaline liquids on $\mathrm{SiO}_{2} / \mathrm{PU}$ coatings, and (c) acidic and (d) alkaline on $\mathrm{SiO}_{2}$ /epoxy resin surfaces. 
was noticed that the water droplet became smaller with time due to the evaporation in air. As shown in Fig. 5a and b, the contact angles of the acidic $(\mathrm{pH}=1)$ droplet and the alkaline $(\mathrm{pH}=14)$ droplet remained larger than $150^{\circ}$ after $50 \mathrm{~min}$. Despite slight decreases in the contact angles with contact time, the sliding angles were still below $10^{\circ}$, indicating that the superhydrophobic $\mathrm{SiO}_{2} / \mathrm{PU}$ coating retained its superhydrophobicity. This result is very important for the application of the silica/PU nanocomposite coating with sustainable superhydrophobicity in corrosive liquids. Fig. 5c and d show the chemical tests on superhydrophobic $\mathrm{SiO}_{2}$ /epoxy resin coatings upon contact with acidic $(\mathrm{pH}=1)$ and alkaline $(\mathrm{pH}=14)$ droplets. The contact angles decreased to $150^{\circ}$ after contacting with the acidic droplet for $25 \mathrm{~min}$ and contacting with the alkaline droplet for $15 \mathrm{~min}$, respectively. The coating lost its superhydrophobicity with further immersion, however, the water droplets could still roll off easily as the sliding angles were below $15^{\circ}$. The superhydrophobic $\mathrm{SiO}_{2} / \mathrm{PU}$ coating has superior chemical durability compared with the superhydrophobic $\mathrm{SiO}_{2} /$ epoxy resin coating.

\subsection{UV irradiation resistance and healability of superhydrophobicity}

Another important concern is the UV resistance of superhydrophobic surfaces in consideration of outdoor applications.
Superhydrophobic composite coatings are usually subject to UV-light exposure, because the presence of large quantities of organic components leads to the oxidation and formation of hydrophilic groups. ${ }^{30}$ Herein, the water contact angles did not significantly change under UV irradiation even after 175 hours of exposure as shown in Fig. S6 in ESI. $\uparrow$ This is because $\mathrm{SiO}_{2}$ is not photoactive, and both $\mathrm{PU}$ and epoxy resin agents are also stable upon UV exposure. Therefore, the $\mathrm{SiO}_{2} / \mathrm{PU}$ and the $\mathrm{SiO}_{2} /$ epoxy resin coatings were UV resistant.

To test the healability of the superhydrophobic $\mathrm{SiO}_{2} / \mathrm{PU}$ and $\mathrm{SiO}_{2} /$ epoxy resin coatings, we used ozone attack to degrade the surface superhydrophobicity. The coatings became hydrophilic after exposure to ozone for $15 \mathrm{~min}$, with water contact angles of $30^{\circ}$ for $\mathrm{SiO}_{2} / \mathrm{PU}$ and $80^{\circ}$ for $\mathrm{SiO}_{2} /$ epoxy resin coatings. Here, our superhydrophobic coatings could be easily healed after heating at $150^{\circ} \mathrm{C}$ for $3 \mathrm{~min}$. As shown in Fig. 6 a, the water contact angles recovered to be greater than $150^{\circ}$ after the healing process, and the hydrophilicity and superhydrophobicity of the coatings could be reversibly transformed for at least 8 cycles. XPS analysis was employed to investigate chemical composites that induced the switching from superhydrophobicity to hydrophilicity as shown in Fig. 6b, and there were three peaks corresponding to $\mathrm{Si}, \mathrm{C}, \mathrm{N}$ and $\mathrm{O}$ on the $\mathrm{SiO}_{2} / \mathrm{PU}$ surfaces. After ozone irradiation for $15 \mathrm{~min}$, the carbon content decreased from 19.2 $\mathrm{wt} \%$ to $17.8 \mathrm{wt} \%$ and the $\mathrm{O}$ content increased from $50.6 \mathrm{wt} \%$ to (a)

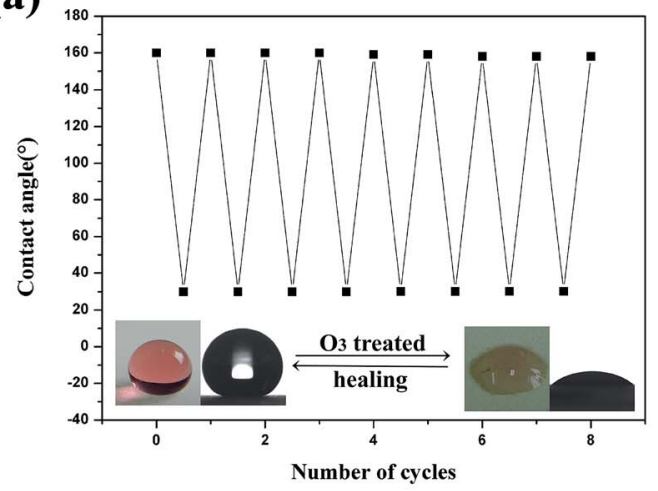

(c)

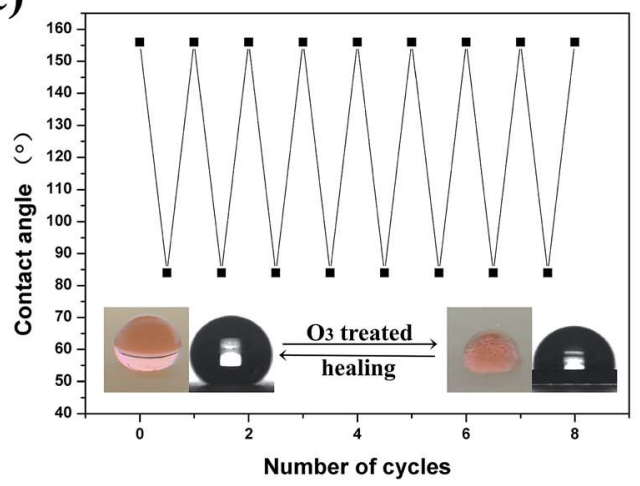

(b)

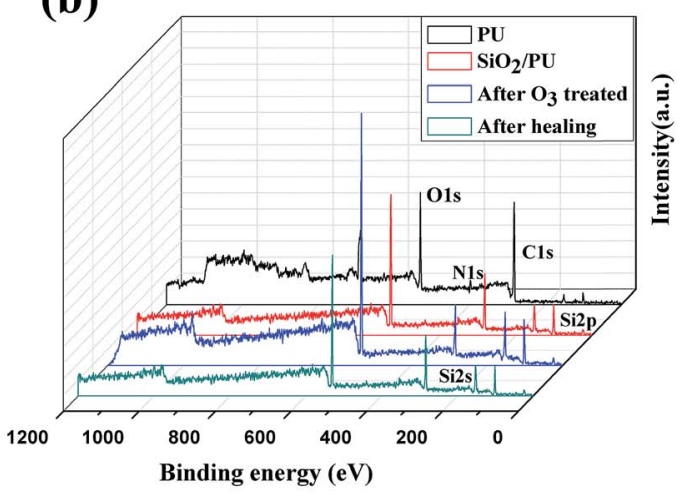

(d)

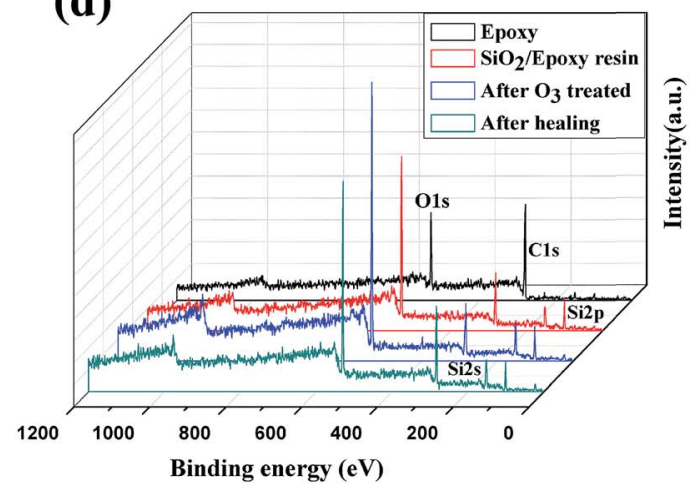

Fig. 6 Reversible superhydrophobic-hydrophilic transition of the as-prepared $\mathrm{SiO}_{2} / \mathrm{PU}$ (a) and $\mathrm{SiO}_{2} /$ epoxy resin (c) under ozone irradiation and heat treatment. XPS analysis of $\mathrm{SiO}_{2} / \mathrm{PU}$ coating (b) and $\mathrm{SiO}_{2} /$ epoxy resin (d) before and after ozone irradiation. 

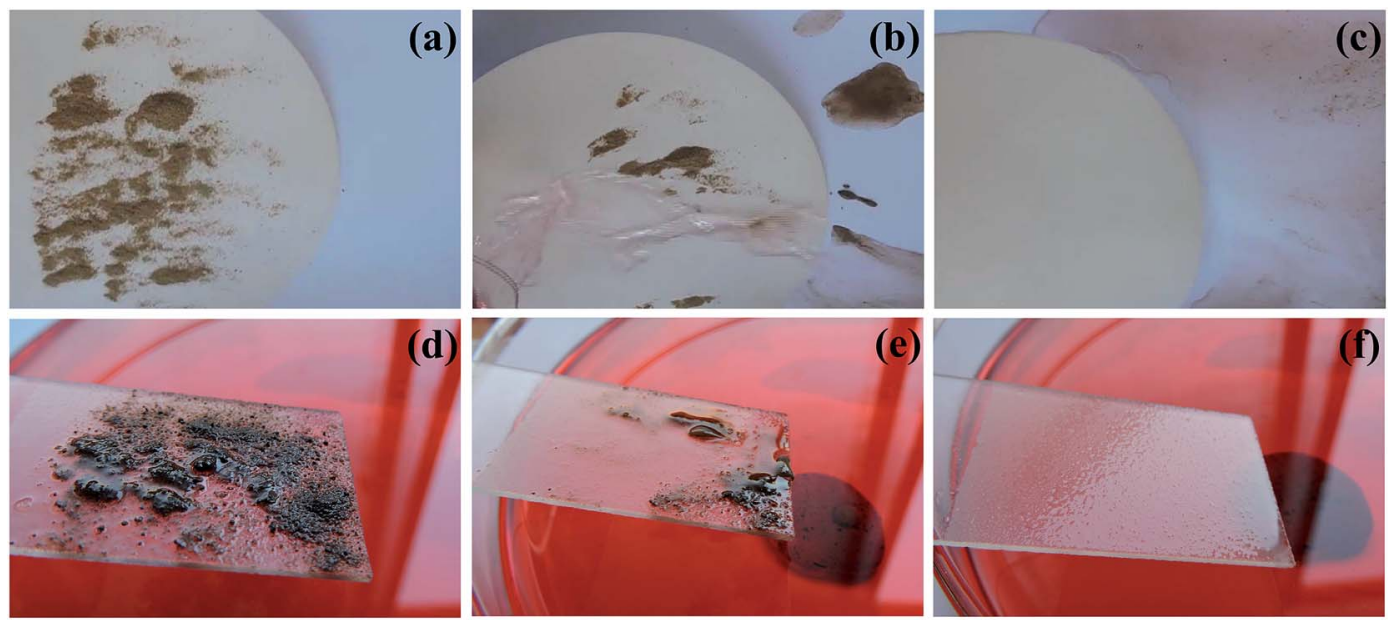

Fig. 7 Self-cleaning properties of $\mathrm{SiO}_{2} / \mathrm{PU}$ in air $(\mathrm{a}-\mathrm{c})$ and contaminated by oil in air $(\mathrm{d}-\mathrm{f})$.

$67.4 \%$. After the healing process, the $\mathrm{C}$ content increased and reached $25.9 \mathrm{wt} \%$, leading to the recovery of superhydrophobicity. Fig. $6 \mathrm{c}$ and d show the switching from superhydrophobicity to hydrophilicity after the ozone attack. In terms of the superhydrophobic $\mathrm{SiO}_{2}$ /epoxy resin coating, the variation of chemical composition was similar to that of $\mathrm{SiO}_{2} / \mathrm{PU}(\mathrm{Table}$ $\mathrm{S} 1$ in the ESI $\dagger$ ). It is believed that the variation of the chemical composition accounts for the transformations in the surface wettability. When the coatings were exposed to the ozone attack, large numbers of hydrophilic species including $-\mathrm{OH}$ groups were formed on the surface as ozone is a strong oxidizer. From Fig. 6 and Tables S1 and S2 in the ESI, $\uparrow$ it can be seen that the $\mathrm{O} /$ $\mathrm{C}$ atomic ratio increased significantly after the ozone attack, indicating that the surface has been oxidized and more hydrophilic components increase. After being heated in the air, the coating recovered its water-repellency. From the XPS analysis, the $\mathrm{O} / \mathrm{C}$ atomic ratio decreased significantly from 5 to 2.5 , which shows that the hydrophobic carbon component increases. It is

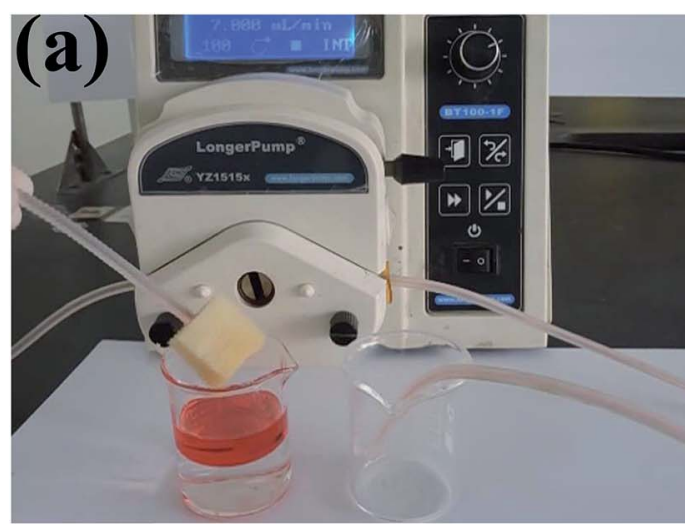

(c)

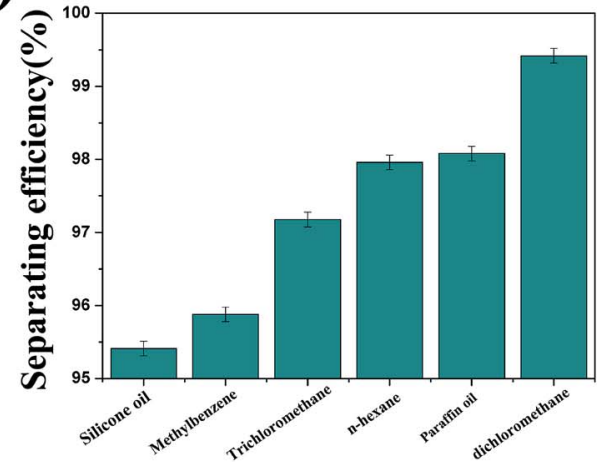

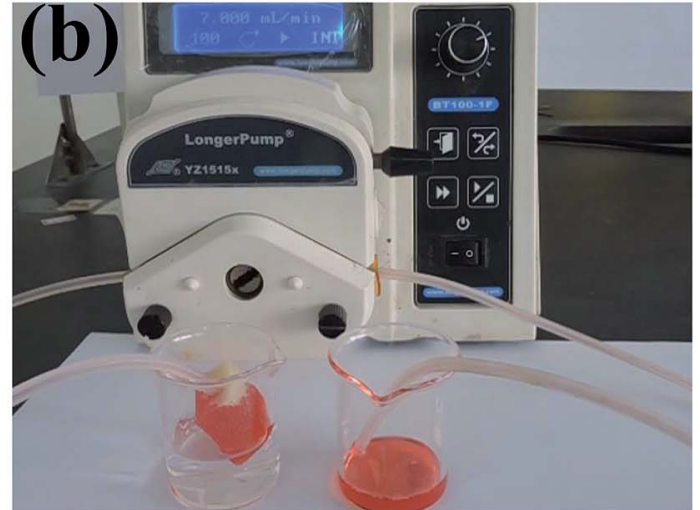

(d)

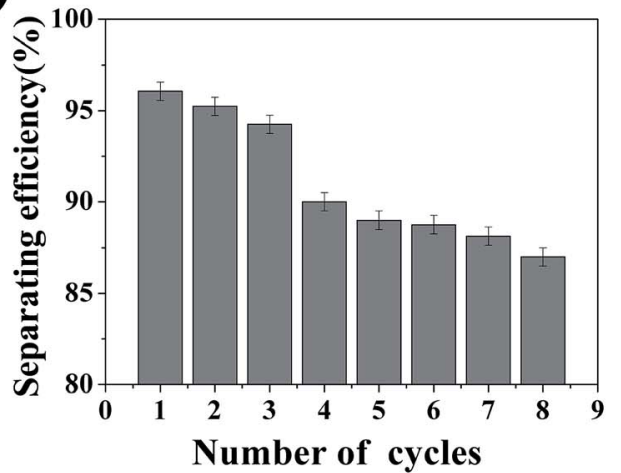

Fig. 8 (a and b) Photographs of the continuous absorption of silicone oil (dyed red) from water. (c) Oil/water separating efficiency. (d) Separating efficiency recyclability of the sponge. 
believed that driven by the reduction of the high interfacial energy between the hydrophilic surface and hydrophobic air, the polar groups $(-\mathrm{OH})$ were "pushed" into the bulk (i.e. the reorientation of polar groups) and the hydrophobic $\mathrm{C}-\mathrm{H}$ chains diffused to the uppermost layer (i.e. the chain diffusion). ${ }^{31,32}$ Therefore, after being heated, the surface recovered its superhydrophobicity.

\subsection{Self-cleaning properties}

In nature, the Lotus leaf is an example of a self-cleaning surface. The rolling motion of water droplets on the leaf surface can pick up the dust and leave the superhydophobic surface clean. Herein, the $\mathrm{SiO}_{2} /$ polymer coatings also show self-cleaning properties. As shown in Fig. $7 \mathrm{a}-\mathrm{c}$ and Video $\mathrm{S} 4, \uparrow$ water could easily take away the dust and leave the treated filter paper surface clean. Interestingly, the coating shows self-cleaning properties even when polluted by oil as shown in Fig. $7 d-f$. When the surface coating was contaminated by oil, the surface structures locked the oil as a lubricating layer, and the lubricated rough surfaces were capable of maintaining droplet mobility regardless of the wetting state. Soil and dust could also be removed by passing water over the surface (Video S5 in ESI $\dagger$ ). Therefore, the surfaces retained their self-cleaning properties even after contamination by oil in air.

\subsection{Oil-water separation}

Materials with extreme wettability, such as superhydrophobic and superoleophilic properties, have been widely used in oil water separations. ${ }^{33}$ However, it is not easy for oil/water separation in the real world because a large amount of polluted water needs to be accumulated first and then filtered. Herein, we used a vacuum system to realize the continuous separation of oil from water without any requirement for collection. Fig. 8a and $\mathrm{b}$ and Video $\mathrm{S} 6 \dagger$ show that the oil and water can be separated with a sponge that is connected with a vacuum system. The silicone oil could be absorbed immediately by the sponge coated with $\mathrm{SiO}_{2} / \mathrm{PU}$ and completely separated from water. The sponge has good absorption capacities with 8-17 times its own weight (Fig. S7 in ESI $\dagger$ ). Fig. 8c shows the oil/water separating efficiency, and it can be seen that the efficiency is above $95 \%$ for all the oil and organic solvents tested, indicating the high continuous separating efficiency. Note that the superhydrophobic PU sponge was recyclable. After being rinsed thoroughly with alcohol and dried, the as-prepared sponges could be reused for oil/water separation for many cycles, as shown in Fig. 8d. The separating efficiency is still more than $85 \%$ after 8 times of recycling.

\section{Conclusion}

In conclusion, we have demonstrated a facile and low-cost method to fabricate superhydrophobic coatings based on combination of polymers with surface functionalized silica nanoparticles. The translucent water-repellent coatings demonstrate mechanical durability, acid/alkaline and UV resistance, and self-cleaning properties even when polluted by oil. Importantly, the fluorine-free coatings have strong adhesion to the substrate and can also be healed by flame treatment. The substrate-independent synthesis provides researchers with new avenues for designing robust superhydrophobic coatings for large-scale indoor and outdoor applications.

\section{Acknowledgements}

This work was supported by the National Nature Science Foundation of China (Grant No. 21403055) and Joint Talent Cultivation Funds of NSFC-HN (Grant No. U1304529).

\section{References}

1 X. Deng, L. Mammen, H. J. Butt and D. Vollmer, Science, 2012, 335, 67-69.

2 Y. Lu, S. Sathasivam, J. Song, C. R. Crick, C. J. Carmalt and I. P. Parkin, Science, 2015, 347, 1132-1135.

3 J. Y. Huang, S. H. Li, M. Z. Ge, L. N. Wang, T. L. Xing, G. Q. Chen and X. F. Liu, J. Mater. Chem. A, 2015, 3, 28252832.

4 T. Darmanin and F. Guittard, J. Mater. Chem. A, 2014, 2, 16319-16359.

5 B. Su, Y. Tian and L. Jiang, J. Am. Chem. Soc., 2016, 138, 17271748.

6 J. Li, R. Kang, X. Tang, H. She, Y. Yang and F. Zha, Nanoscale, 2016, 8, 7638.

7 Q. Liu, D. X. Chen and Z. X. Kang, ACS Appl. Mater. Interfaces, 2015, 7, 1859-1867.

8 X. Deng, L. Mammen, Y. F. Zhao, P. Lellig, K. Müllen, C. Li, H. J. Butt and D. V. Groten, Adv. Mater., 2011, 23, 2962-2965.

9 B. C. Li and J. P. Zhang, Chem. Commun., 2016, 52, 27442747.

10 X. C. Tian, S. Shaw, K. R. Lind and L. Cademartiri, Adv. Mater., 2016, 28, 3677-3682.

11 X. Zhang, Y. G. Guo, H. Z. Chen, W. Z. Zhu and P. Y. Zhang, J. Mater. Chem. A, 2014, 2, 9002-9006.

12 C. H. Xue, Z. D. Zhang, J. Zhang and S. T. Jia, J. Mater. Chem. A, 2014, 2, 15001-15007.

13 Y. P. Liu, H. F. Liu, Y. G. Feng, Z. L. Liu, H. Y. Hu, B. Yu, F. Zhou and Q. J. Xue, RSC Adv., 2016, 6, 21362-21366.

14 Q. Wei, C. Schlaich, S. Prévost, A. Schulz, C. Böttcher, M. Gradzielski, Z. Qi and R. Haag, Adv. Mater., 2014, 26, 7358-7364.

15 Y. Li, S. Chen, M. Wu and J. Sun, Adv. Mater., 2014, 26, 33443348.

16 Y. Li, L. Li and J. Sun, Angew. Chem., 2010, 122, 6265-6269. 17 H. J. Perera, B. K. Khatiwada, A. Paul, H. Mortazavian and F. D. Blum, J. Appl. Polym. Sci., 2016, 133, 44072.

18 B. R. Sedai, B. K. Khatiwada, H. Mortazavian and F. D. Blum, Appl. Surf. Sci., 2016, 386, 178-186.

19 S. Alexander, J. Eastoe, A. M. Lord, F. Guittard and A. R. Barron, ACS Appl. Mater. Interfaces, 2016, 8, 660-666.

20 F. Xue, D. M. Jia, Y. Li and X. L. Jing, J. Mater. Chem. A, 2015, 3, 13856-13863.

21 H. Sojoudi, M. Wang, N. D. Boscher, G. H. McKinley and K. K. Gleason, Soft Matter, 2016, 12, 1938-1963. 
22 T. Verho, C. Bower, P. Andrew, S. Franssila, O. Ikkala and R. H. A. Ras, Adv. Mater., 2011, 23, 673-678.

23 Y. Lu, S. Sathasivam, J. L. Song, F. Z. Chen, W. J. Xu, C. J. Carmalta and I. P. Parkin, J. Mater. Chem. A, 2014, 2, 11628-11634.

24 W. B. Zhang, Z. Shi, F. Zhang, X. Liu, J. Jin and L. Jiang, Adv. Mater, 2013, 25, 2071-2076.

25 H. W. Liang, Q. F. Guan, L. F. Chen, Z. Zhu, W. J. Zhang and S. H. Yu, Angew. Chem., Int. Ed., 2012, 51, 5101-5105.

26 X. C. Dong, J. Chen, Y. M. Ma, J. Wang, M. B. Chan-Park, X. M. Liu, L. H. Wang, W. Huang and P. Chen, Chem. Commun., 2012, 48, 10660-10662.

27 X. Zhang, D. F. Zhi, W. Z. Zhu, S. Sathasivam and I. P. Parkin, RSC Adv. , 2017, 7, 11362-11366.
28 X. H. Li, Z. Cao, Z. J. Zhang and H. X. Dang, Appl. Surf. Sci., 2006, 252, 7856-7861.

29 X. Zhang, Y. G. Guo, H. Z. Chen, W. Z. Zhu and P. Y. Zhang, J. Mater. Chem. A, 2014, 2, 9002-9006.

30 Q. F. Xu, Y. Liu, F. J. Lin, B. Mondal and A. M. Lyons, ACS Appl. Mater. Interfaces, 2013, 5, 8915-8924.

31 F. Z. Chen, J. Y. Liu, Y. Cui, S. Huang, J. L. Song, J. Sun, W. J. Xu and X. Liu, J. Colloid Interface Sci., 2016, 470, 221228.

32 F. Z. Chen, W. J. Xu, Y. Lu, J. L. Song, S. Huang, L. Wang, I. P. Parkin and X. Liu, Micro Nano Lett., 2015, 10, 105-108. 33 M. W. Lee, S. An, S. S. Latthe, C. M. Lee, S. Hongand and S. S. Yoon, ACS Appl. Mater. Interfaces, 2013, 5, 10597-10604. 